\title{
Crucial data on REACH not disclosed
}

\section{Disagreement flares up over the number of animals required to implement Europe's chemical-safety law.}

A leading toxicologist has accused the research arm of the European Commission of suppressing a scientific study that could have changed the course of chemical safety legislation in Europe.

The study predicted that millions more animals than the commission had estimated would be needed to test chemicals under REACH (Registration, Evaluation, Authorisation and Restriction of Chemicals), sometimes dubbed the most complex legislation in the history of the European Union (EU).

"It is my strong belief that some decisions on REACH would have been different in the light of these data," says Thomas Hartung, former head of the European Centre for the Validation of Alternative Methods (ECVAM) in Ispra, Italy, who led the study.

ECVAM is part of the Joint Research Centre (JRC), the commission service that carries out research to inform European polices. The allegations came to light in a commission-led inquiry into whether Hartung, now a toxicologist at Johns Hopkins University in Baltimore, Maryland, broke commission rules by publishing an Opinion piece on REACH in Nature last year without asking the JRC's permission (see Nature 460, 1080-1081; 2009).

Hartung now claims that the JRC tried to keep his research under wraps just as REACH was in the final, politically sensitive stages of formulation. In a statement to Nature, issued on behalf of all JRC and commission officials involved, the commission unequivocally denies any wrongdoing. "The European Commission robustly refutes any suggestion that it has misled anyone or sought to conceal information over the effects of the REACH legislation on animal testing. Such suggestions are unfounded."

REACH became law in June 2007. It stipulates that all chemicals sold in the EU in annual quantities of more than one tonne (at least 30,000 compounds) must be registered, along with toxicity data, by 2018. Back in 2005, when REACH was taking shape, it was already clear that more stringent chemical-safety testing would need many more tests on laboratory animals. Some politicians were deeply concerned about the ethics of this; others worried about the financial costs, or whether there were enough laboratories to conduct the tests. For example, Gunter Verheugen, who was then the commission's vicepresident and responsible for enterprise and industry, said in November 2005 that REACH would not be ethically viable if it required excessive additional use of animals. A spokesman

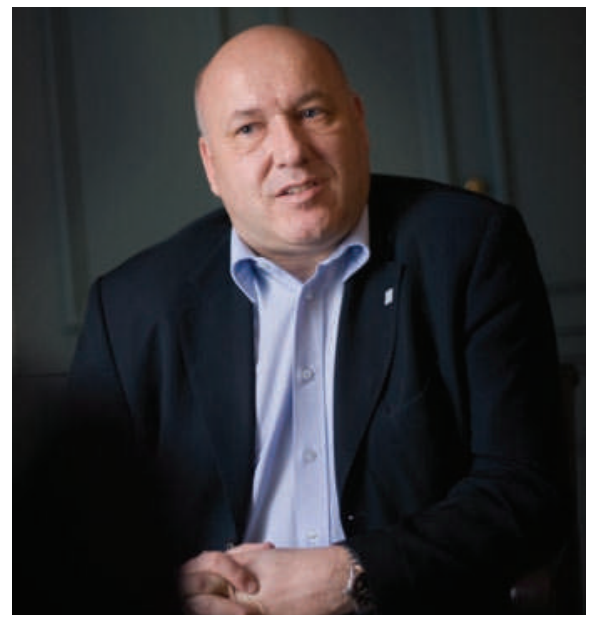

Thomas Hartung led European Commission research on the use of animals in chemical tests.

for the Brussels-based European Parliament Intergroup on the Welfare and Conservation of Animals, a cross-party group of parliament members that promotes awareness on animalwelfare issues, says that if the commission had cited higher estimates of animal use, there would have been greater pressure to ensure more funding for alternative testing methods.

The JRC had already produced two such estimates in 2003 and 2004. The conclusion was that, in a best-case scenario, REACH would require 2.1 million to 3.9 million animals by 2018. These figures were cited by the JRC and commission throughout the development of $\mathrm{REACH}$, and are still found on its website. But the studies were not peer reviewed, and were widely criticized by Hartung and other toxicologists for not taking into account the offspring produced during reproductive toxicology tests over two generations of animals, as required by the EU's lab animals directive at that time.

Hartung was commissioned by the JRC to come up with a new estimate. In September 2006, he delivered a verdict that had been peer reviewed by a panel of academic and industry experts, suggesting that a minimum of 8 million to 9 million animals would be required. This was in line with two other independent, peer-reviewed studies conducted on the impact of REACH. A 2001 study by researchers at the Institute for Environment and Health at the University of Leicester, UK, and another by toxicologists at the Federal Institute for Risk Assessment in Berlin (BfR), in 2004, found that the legislation would require between 7.5 million and 10 million animals. Although these studies were available in the literature, greater weight was given to the commission's estimates during debates on REACH. But Manfred Liebsch a toxicologist at the BfR who contributed to the study, told Nature that the JRC's original lower estimates were "unrealistic" and that Hartung's 2006 estimate was more credible.

The differences between these estimates was partly due to varying degrees of optimism over the use of non-animal methods such as computer models of biological response to chemicals. Hartung took part in another JRC study on this matter, collaborating with two other toxicologists including Martin Barratt, who runs a predictive toxicology consultancy in Bedford, UK. The study, completed in October 2006, found that around $50 \%$ of chemicals under REACH could be tested by computer simulation. The result contrasted with the JRC's 2003 study, which said that up to $92 \%$ of some key toxicology tests could use such methods. Barratt says the JRC did not give clearance to publish the study: "I have no idea why they said we could not publish it." The research remains unpublished, and the commission did not respond to Nature's questions on this matter.

\section{Margin for error}

About a month after delivering his study estimating total animal use, Hartung was growing impatient. He e-mailed his superior, Elke Anklam, director of the JRC's Institute for Health and Consumer Protection (IHCP), on 27 October 2006, calling for his study to be published so that it could inform the legislation. "I consider it embarrassing, how the outdated numbers are continuously referred to," he wrote. He e-mailed Anklam again on 8 November 2006 with a letter for the JRC's then acting director general, Roland Schenkel, making the same point. Hartung says he could not make the study public himself at that time, as he was bound by the commission's confidentiality rules. The research had still not been published when the European Parliament approved REACH on 13 December 2006. A commission briefing document on REACH released on the same day made no reference to Hartung's study and quoted the lower estimates of animal use.

On 16 January 2007, Hartung met with Anklam, Schenkel and advisers to then research commissioner Janez Potočnik to discuss the REACH animal-use estimates, among other topics. Hartung claims that, before the meeting, 
Schenkel told him to "downplay the discrepancies" between the three JRC studies. Hartung says he complied with the request. The commission, speaking to Nature on Schenkel's behalf, would not comment on this conversation.

Hartung says that a summary, rather than a full version of his study, was published on the IHCP website in January 2007 (bearing the date October 2006), but was removed several months later. In its statement to Nature, the commission said: "No research was 'suppressed'. The Commission's assessments
"The European Commission robustly refutes any suggestion that it has sought to conceal information over the effects of the REACH legislation." as adopted) to count estimates of offspring in reproductive toxicity tests." Any such estimates contain a "margin for error in both directions". The commission says that animal use will decrease over time, in part because it has invested $€ 200$ million (US\$270 million) in non-animal methods over the past 20 years.

\section{Matter of opinion}

The Nature Opinion article that prompted the inquiry into Hartung claimed that generating REACH data could require up to 54 million animals and cost are never the view of one individual, but are arrived at by thorough internal processes of peer review and quality assurance, followed in this case.

"These figures have been adapted over time and in line with evolving circumstances. This process has been transparent at all times," it adds. "The different estimation (nine million) in the 2006 report from the 2003 and 2004 reports derives mainly from the new requirement (stemming from the REACH regulation almost $€ 10$ billion over the next decade, rendering the legislation unfeasible. This figure took into account the projected growth of the EU and the chemical industry, and also assumed that two-generation reproductive toxicology tests would still be used. At a 24 March hearing, Hartung defended himself by claiming that the analysis was not based on any data collected while he was at the JRC. The commission says it will not comment on the inquiry.
Responding to Hartung's Nature article, the European Chemicals Agency (ECHA) in Helsinki, set up in 2007 to manage REACH, agreed that estimates of 2.6 million animals were too low, noting instead the BfR estimate of 9 million animals. A commission statement released at the same time also quotes the 9-million figure. Speaking to Nature, Jukka Malm, director of assessment at the ECHA, said the agency was "not aware" of Hartung's 2006 study, adding that it had independently concluded that 9 million animals was the most reliable estimate.

Although Liebsch supports Hartung's work, he worries that the controversy is distracting attention from work led by the Organisation for Economic Co-operation and Development (OECD) to finalize guidelines on a reproductive toxicity test that would use only one generation rather than two, potentially halving the number of animals required and making the legislation feasible (see Nature 463, 142-143; 2010). The OECD must agree on the guidelines before December 2010 so that they can be included in the tests put forward by chemical manufacturers to meet REACH's requirements.

A decision on Hartung's case is pending. Natasha Gilbert 